\title{
Pulmonary Hypertension and Portal Venous System Thrombosis
}

\author{
S. LAL AND E. FLETCHER \\ From the Cardiovascular Unit, Belfast City Hospital
}

Necropsy reports suggest that pulmonary hypertension may occur as a result of portal hypertension with portal venous thrombosis (Naeye, 1960). Obstructive pulmonary vascular disease appears to be the underlying pathology leading to chronic cor pulmonale with right ventricular hypertrophy. Nevertheless, clinical cases have rarely been reported. The haemodynamic changes and radiological findings of a case are now described.

\section{Case Report}

A woman aged 41 years was admitted to hospital with advanced congestive heart failure. There was a right ventricular heave, pulmonary systolic murmur, and palpable second heart sound. The spleen was palpable three finger breadths below the costal margin. For one year before admission she had increasing breathlessness, recurrent small haemoptyses, and syncopal attacks. The presence of pulmonary hypertension was confirmed by cardiac catheterization. Her past history was significant with regard to the splenomegaly. She had infective hepatitis at the age of 14 years. In her 28th year she had a profuse haematemesis, for which laparotomy was carried out in Hong Kong. No cause for 'the haematemesis was found.

Cardiac Catheterization Data. Pulmonary artery pressure, $135 / 84 \mathrm{~mm}$. $\mathrm{Hg}$ (mean $88 \mathrm{~mm}$. $\mathrm{Hg}$ ); right ventricular pressure, $135 / 11 \mathrm{~mm}$. $\mathrm{Hg}$; pulmonary wedge pressure, $1 \mathrm{~mm}$. $\mathrm{Hg}$; mean right atrial pressure, $8 \mathrm{~mm}$. $\mathrm{Hg}$; mean hepatic wedge pressure, $11 \mathrm{~mm}$. $\mathrm{Hg}$; brachial artery pressure, $109 / 65 \mathrm{~mm}$. Hg. Pulmonary vascular resistance, 18 Wood units (normal, 1-2 Wood units). Cardiac output, 5.06 litres per minute. Arterial oxygen saturation at rest, 89 per cent, and after breathing 100 per cent oxygen for 5 minutes, 100 per cent. There was no intracardiac shunt.

The significant findings were severe pulmonary hypertension, the pulmonary artery pressure exceeding the systemic arterial pressure, arterial desaturation at rest, and a normal cardiac output.

$9^{\star}$
Biochemical Data. Total serum proteins, $6.4 \mathrm{~g} . / 100$ ml. ; albumin, $2.8 \mathrm{~g} . / 100 \mathrm{ml}$; ; $\alpha_{1}$-globulin, $0.1 \mathrm{~g} . / 100 \mathrm{ml}$.; $\alpha_{2}$-globulin, $0.7 \mathrm{~g} . / 100 \mathrm{ml}$.; $\beta$-globulin, $0.8 \mathrm{~g} . / 100 \mathrm{ml}$; $\gamma$-globulin, $2 \mathrm{~g} . / 100 \mathrm{ml}$. Albumin/globulin ratio, 0.8. Bromsulphalein retention, 27 per cent at 45 minutes. Thymol turbidity normal. In the light of clinical data and results of other investigations, these biochemical abnormalities suggest liver dysfunction due to cirrhosis.

In addition to the above investigations, the serum electrolytes were normal, $\mathrm{Hb} 15.6 \mathrm{~g} . / 100 \mathrm{ml}$. In view of the residence in the tropics, a schistosome complement-fixation test was carried out to exclude possibility of schistosome lung disease: this was negative. Pulmonary function tests showed moderate reduction in ventilatory function $\left(\mathrm{FEV}_{1 \cdot 0}=60 \cdot 7 \%\right.$ of $\left.\mathrm{FVC}\right) . \mathrm{PCO}_{2}$, $30 \mathrm{~mm}$. $\mathrm{Hg}$.

Radiological Data. Radiographs of the chest between January 30, 1962, and November 12, 1967, confirmed progressive prominence of the pulmonary artery conus complex. This was chiefly due to marked enlargement of the pulmonary artery shown by angiocardiogram (Fig. 1). A splenovenogram confirmed obstruction of the splenic vein with anastomotic vessels (Fig. 2). This was also demonstrated by coeliac axis angiogram which also showed a lack of normal filling of the portal vein. A hepatic artery angiogram was abnormal, with diminished vascularity of the liver in keeping with fibrous replacement due to cirrhosis.

\section{Discussion}

Chronic cor pulmonale with pulmonary hypertension in association with portal venous system thrombosis is an unusual sequela of cirrhosis of the liver. A likely explanation may be recurrent microembolism of the small pulmonary arteries from a source in the obstructed portal venous system Mantz and Craige (1951) demonstrated a large spostaneous portocaval shunt emptying into the eft innominate vein at necropsy. Their patient had occlusion of the small pulmonary arteries by ogan- 
ized thrombi. More recently, Lai, McFadzean, and Yeung (1968) have described microembolism of the lungs in hepatic fibrosis due to recurrent cholangitis. They attributed the passage of small emboli to the lungs to the presence of small hepatic arteriovenous fistulae. It appears reasonable to assume that small emboli may pass from portal venous system thrombi via collateral venous channels to the lungs. The ova of Schistosoma mansoni, measuring $140 \times 60 \mu$, can reach the lungs via portal venous system by collateral channels. In addition, the injection studies of Calabresi and Abelmann (1957) demonstrated that anastomic channels at least $40 \mu$ in diameter linked the portal and systemic veins. Embolization of the lungs from portal venous system thrombosis would, therefore, involve minute emboli only. The case described can be explained on such a hypothesis based on anatomical facts. Portal venous obstruction would probably enlarge such communications so that repeated microembolism of the lungs results, with resultant pulmonary hypertension and ultimate congestive failure due to chronic cor pulmonale.

\section{Summary}

A case is described of pulmonary hypertension

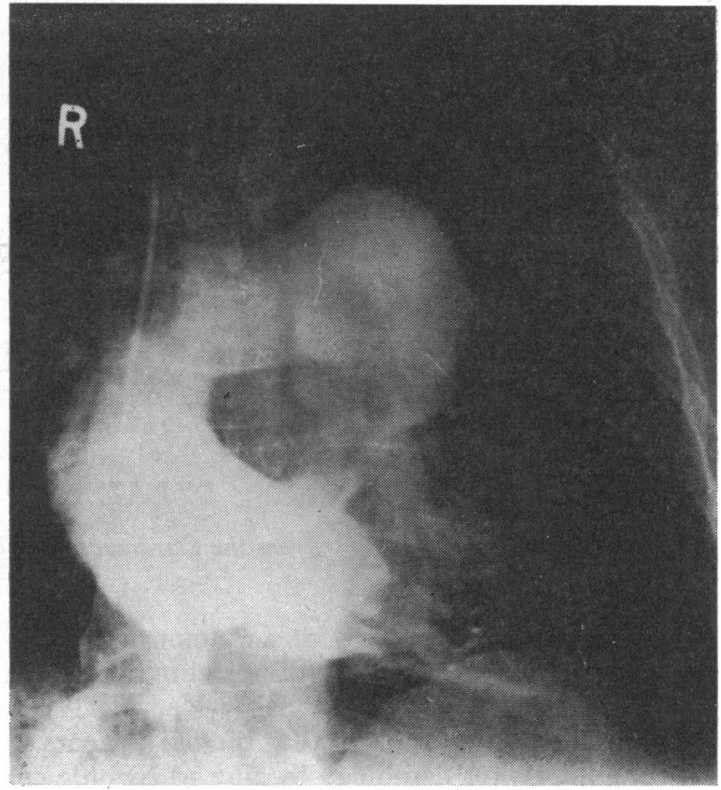

FIG. 1.-Right ventricular angiogram. The pulmonary artery is greatly enlarged. Dye has filled the right atrium due to tricuspid insufficiency.

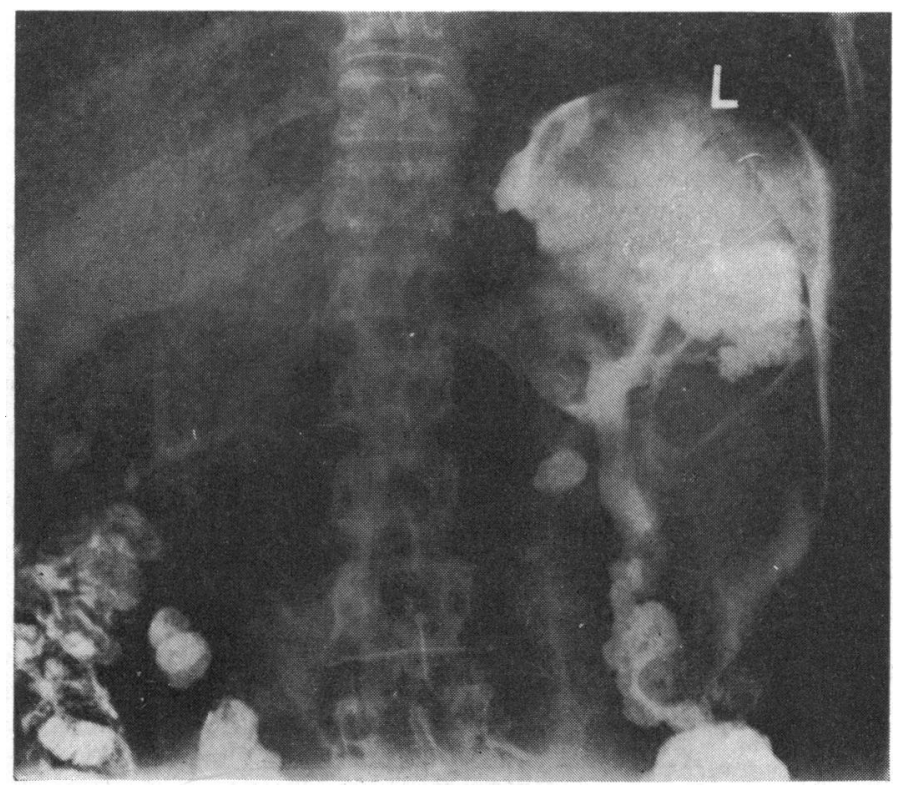

FIG. 2.-Percutaneous splenovenogram. The splenic vein is obstructed. An enlarged collateral channel is present. The portal vein has not filled. A small amount of contrast has escaped around the capsule of the spleen. 
complicating portal venous thrombosis with congestive heart failure. The significant symptoms were breathlessness, syncope, and recurrent small haemoptyses. The pathological process is likely to be recurrent microembolism of the lungs via collateral channels from the portal venous thrombosis.

We wish to thank Dr. E. McIlrath and Dr. W. A. Brown for their help with coeliac axis and hepatic artery angiograms.
References

Calabresi, P., and Abelmann, W. H. (1957). Porto-caval and porto-pulmonary anastomoses in Laennec's cirrhosis and in heart failure. 7 . clin. Invest., 36, 1257.

Lai, K. S., McFadzean, A. J. S., and Yeung, R. (1968). Microembolic pulmonary hypertension in pyogenic cholangitus. Brit. med. $\mathcal{F}$., 1, 22.

Mantz, F. A., and Craige, E. (1951). Portal axis thrombosis with spontaneous portacaval shunt and resultant cor pulmonale. Arch. Path., 52, 91.

Naeye, R. L. (1960). "Primary" pulmonary hypertension with coexisting portal hypertension. A retrospective study of 6 cases. Circulation, 22, 376. 